\title{
Study on the Peace War Transformation Mechanism of Equipment Maintenance Mobilization
}

\author{
Peng Dong ${ }^{1, a}$, Zhaohui Luo ${ }^{1, b}$ and Kewen Wang ${ }^{1, c}$ \\ ${ }^{1}$ Department of Management Engineering, Naval University of Engineering, \\ Wuhan, Hubei, 430033, China \\ arocdong@163.com, ${ }^{\mathrm{b}}$ navyer@163.com, ${ }^{\mathrm{c}} 704860966 @ q q . c o m$
}

Keywords: Equipment Maintenance Mobilization; Peace War Transformation; Mechanism

\begin{abstract}
Considering the current trend of the development of high technology local war, the demands and challenges of mobilization of equipment maintenance and Peace war transformation, the article aim at analyzing the basic characteristics of equipment maintenance mobilization tasks, researching important influence factors and the main body of the Peace war transformation mechanism to mobilize the equipment maintenance, building the objective mechanism of Peace war transformation to mobilize the equipment maintenance. It has important theoretical guidance and reference significance to realize a rapid and effective mobilization of equipment maintenance and Peace war transformation.
\end{abstract}

\section{Introduction}

Under the background of modern high technology local war, the more advance equipment has the more urgent needs for high technical talents. Corresponding to this, the information-based war greatly increase the technological content of equipment mobilization, now we not only need to urge the army and local research institutes to speed up developing and producing high-tech equipment and a variety of maintenance materials, also need to mobilize local reserve force to provide technical advice, solve technical problems, complete the task of equipment maintenance in wartime. Under the condition of high technology war, as the equipment degree become high, the old transformation mechanism is incapable of meeting the requirements of equipment maintenance in the modern war mobilization, it is necessary to establish new transformation mechanism to adapt to modern high technology local war. In this context, this article aim to analyze features of equipment maintenance to mobilize, to research influence factors and main body of equipment safeguard transformation, to establish equipment maintenance under the condition of high technology local war mobilization transformation target model, and then construct the reasonable mechanism of transformation from peacetime to wartime.

\section{Analysis of Characteristics of Equipment Maintenance Mobilization}

We should first analyze the basic characteristics of equipment maintenance mobilization work. By researching the modern high technology local war mobilization of equipment maintenance, we know the characteristics of equipment maintenance mobilization , as the following [1-3]:

Mobilize time is tight. This requires supplement to the equipment maintenance is fast, the national economy turn into preparation for war is fast, reorganization of industrial structure, expanding security equipment military production is fast.Mobilization of science and technology has a highlighted status. It's great important to develop new technology research, to establish a complete system of military scientific research, to concentrate a large number of researchers into equipment maintenance.Mobilization is flexible. If have the preparation to cope with various war mobilization, strengthening the wartime rapid response ability, we can quickly respond to high technique local war.Mobilization is well-prepared. To meet the need of high-tech local war, we need careful 
mobilization plan, and constantly improving the system of laws and regulations, also the leadership, strengthening the construction of reserve forces, developing comprehensive national strength.

\section{Analysis of the Peace War Transformation Mechanism}

Under the condition of high technique local war background, to complete perfectly mobilize the equipment maintenance tasks, we should especially pay attention to the transformation issues, the effective work of transformation, to ensure that the equipment maintenance in peacetime to wartime benefit fully, smooth transformation. Conversion problem analysis mainly from influence factors, task subject, to carry out.

Equipment maintenance mobilization as a national defense mobilization and an important part of national defense science, technology and industry, its development and run by internal and external equipment mobilization system comprehensive effect and the influence of various complex conditions. And discussed conversion is part of the equipment maintenance mobilization, so on the influence factors of equipment mobilization and the corresponding impact on its, these factors include: one is the development strategy of national defense and military strategy. Development strategy of national defense and military strategy is macroscopic policy influence factors of equipment maintenance to mobilize conversion. If the government attaches great importance to the Peace war transformation mechanism to mobilize the equipment maintenance in national defense construction and national defense mobilization and the role of the future high-tech local war, maintenance equipment safeguard discussed transformation and defense science, technology and industry overall coordinated development. That has very important strategic significance to promote the construction of equipment maintenance mobilization, enhance mobilization potential and ensure the reliability of the implementation [4]. The second is equipment safeguard demand. Equipment safeguard demand is the basis of transformation.

Equipment safeguard to the wartime mobilization is usually maintenance system maintenance system transformation process, has different main body in each stage [5]. One is the body of the peacetime maintenance. Including military enterprise, the local military enterprise, mainly is the production of security equipment and technical maintenance. Civilian goods after equipment production license certification enterprises, private enterprises, engaged in production of form a complete set of security resources of producing parts, components, and even some critical parts. It is discussed the body of the transition phase. Enter the mobilization production stage, equipment maintenance organization management model is different, the attend enterprise is relatively complex. Including local military industrial enterprises, through a series of measures to improve production capacity, increase production, including increased production shift, process simplified, and the composition of various forms of security team to help with the equipment maintenance work. Army military enterprise or mobilization of enterprises production line enabled, equipment mobilization program implementation. It is civilian goods enterprises and private enterprises. Then they can join in military industry products production. However, when want to undertake large quantities of production, we will have problem, its production and management, organization, is unlike military industrial enterprises, such as it is difficult to adapt to the requirements of equipment maintenance.

\section{Analysis on Conversion Mechanism of Equipment Maintenance Mobilization}

Establishing reasonable and effective discussed conversion mechanism to mobilize the equipment maintenance, that is the basis of complete equipment safeguard mobilization tasks, the basic requirement of equipment maintenance work for high technology local war on.

One is the purpose. Equipment maintenance war mobilization discussed conversion is a special activity, which a country take with the intention of meeting the need for equipment, planned and organized to improve the ability of weapon equipment in wartime guarantee peace war transform ability of. The second is the characteristics of planning. It's reflected that the discussed transformation must be included in the development of national defense and economic mobilization, 
and the entire social and economic development plan, equipment maintenance to mobilize discussed transformation target mode of operation must follow the rules of market economy and accept the government macroeconomic regulation and control. It is integrity. Equipment maintenance to mobilize discussed transformation target mode is a specific function of the organic whole which consists of several interrelated, interaction of elements. It is dynamic. Not only is the factor of discussed conversion varied, the structure of function also is not a single value. Contacting the probability, equipment maintenance mobilization discussed conversion shows a variety of functions of the equipment maintenance system. It is mutual conditionality. It means giving full play to the mobilization and ensuring mutual restriction relationship between equipment safeguard discussed transformation and target mode of interaction the elements.

Building discussed conversion mechanism to mobilize the equipment maintenance, which can both adapt to the socialist market economic system and meet the requirements for high technology local war in the new period, we should start from the following aspects: one is to improve authority discussed conversion equipment safeguard mobilization organizations in the new period. Equipment safeguard mobilization system requires countries to establish a system of macroeconomic regulation and control, which is scientific authoritative and efficient, to ensure strong guidance and effectively discussed all kinds of equipment maintenance mobilization, conversion of implementation. Therefore, the mobilization mechanism must be able to imply centralized and unified leadership, realize scientific decision and ensure the function of the order. The second is ascending weapon equipment guarantee mobilization discussed conversion mode in the new period. Equipment maintenance mobilization activity is an organic whole which is multi-sectoral, multi-level, huge and complex in a certain range of time and space crisscross. When constructing the mobilization system of national defense economy, we must know the fact that it is necessary for the system to establishing a complete system of model system. Therefore, we must follow the national scientific prediction of the future war and military strategy, when design and establish national defense economic construction of medium and long-term development goals.

Under the condition of high technique local war, discussed conversion mechanism to mobilize the equipment maintenance includes three levels: organization, the main body layer, maintenance layer and circulation. In equipment maintenance to mobilize discussed conversion mode, as discussed conversion equipment safeguard mobilization organization level, government has functions, including equipment safeguard mobilization discussed transformation planning and policy guidance, organization and coordination. As a maintenance layer, the function of universities and research institutes is mainly to provide equipment maintenance of new and high technology and Peace of equipment maintenance to mobilize talents. As circulation layer, business enterprise's functions is to provide equipment layer and maintenanceing layer supply channels, speed up the equipment maintenance mobilization stage equipment supply and transport. This model must follow the rules of market economy, government policy maintenance for security, so it is different from previous patterns. Thus, to some extent, it can promote equipment safeguard mobilization discussed conversion leapfrog development in our country. Conversion mechanism is shown in Fig. 1.

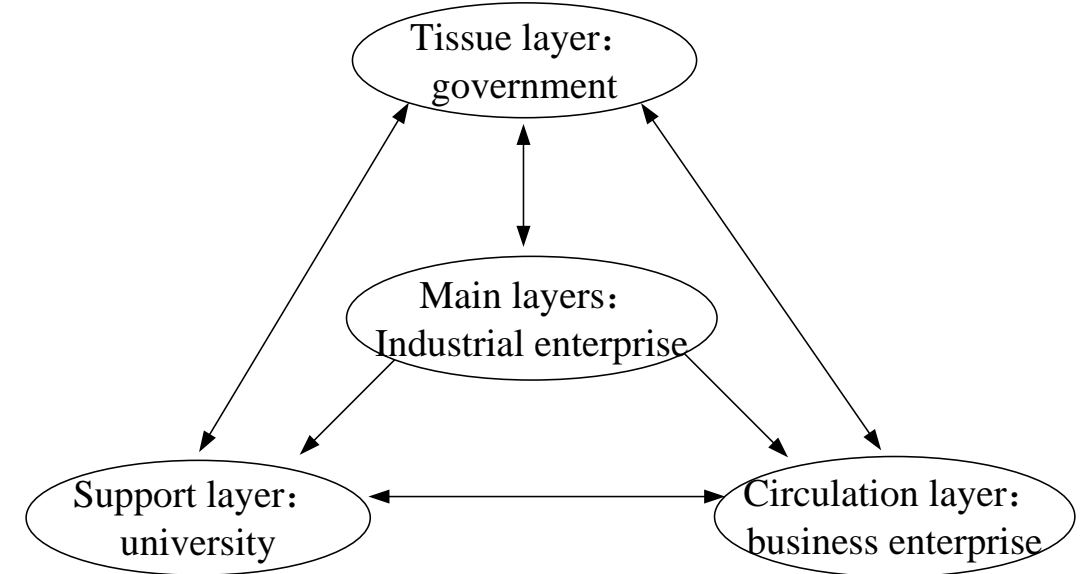

Fig.1 Discussed conversion mechanism to mobilize the equipment maintenance in the new period 
Tissue layers: it's the equipment maintenance to mobilize discussed conversion of command and coordination mechanism, the main function as followings: determining equipment safeguard mobilization discussed transformation system of laws and regulations and related planning and policy guidance, coordination of equipment maintenance to mobilize discussed convert each work and interest, converting discussed the implementation of the supervision and control of mobilization, directly deciding the major problems in equipment maintenance mobilization.

Main layers: it's the implementation of the organization level guidelines and policies formulated by the institution, its main function is to plan and organize comprehensively equipment maintenance to mobilize discussed conversion work, to organize survey of equipment maintenance mobilization potential, to prepare the equipment maintenance mobilization program, to strengthen the equipment's capacity for independent innovation, increase the technological content of products, to convert the equipment maintenance to mobilize discussed specific work, and to provide the biggest technical guarantee maintenance, etc.

Maintenance layer: it's the maintenance equipment safeguard mobilization discussed transformation of colleges and universities and research institutes, main function is in accordance with the organization of the implementation of the plan, in equipment maintenance to mobilize discussed conversion process.

Circulation layer: as the circulation layer, business enterprise provides safeguard equipment supply channels for mainly layer and maintenanceing layer.

\section{Conclusions}

Based on equipment maintenance to mobilize discussed transformation problem, the article analyses the characteristics of equipment maintenance to mobilize, researches the influencing factors and the main body of discussed conversion equipment safeguard mobilization, builds the discussed conversion mechanism to mobilize the equipment maintenance. In this paper, the author studies on mechanism of the reality, the article has certain guiding significance for mobilization of equipment maintenance discussed transformation research.

\section{References}

[1] Dong Li, Jindong Duan: High technology war and foreign weapons and equipment mobilization management system reform[J]. Journal of nanjing institute of politics, 2002, (4) : 23-26..

[2] Lin Li, Guolong Chen: New period weapon equipment mobilization system of transverse research[J]. Journal of national defense mobilization, 2005, (3) : 19-22.

[3] Yan Dong: Weapon equipment mobilization research review[J]. Journal of military school of economics, 2004, (4) : 38-40.

[4] Miao Yu: Aim at the informationization war To strengthen the construction of equipment maintenance to mobilize information[J]. Journal of defense technology, 2004, (6) : 6-7.

[5] Jinpo Yu: The weaponry mobilization in the new period of shallow standardization work[J]. Journal of national defense mobilization, 2005, (6) : 39-41. 